Elsevier required licence: $(c)<2018>$. This manuscript version is made available under the CC-BY-NC-ND 4.0 license http://creativecommons.org/licenses/by-nc-nd/4.0/ 


\title{
Oligopoly Game: Price Makers Meet Price Takers*
}

\author{
Mikhail Anufrieva, $\uparrow \quad$ Dávid Kopányi b,c, $\ddagger$
}

\author{
${ }^{a}$ Economics Discipline Group, University of Technology Sydney, \\ P.O. Box 123, Broadway, NSW2007, Sydney, Australia. \\ b CeNDEF, Amsterdam School of Economics, University of Amsterdam, \\ P.O. Box 15867, 1001 NJ Amsterdam, The Netherlands \\ c Tinbergen Institute, The Netherlands
}

\begin{abstract}
The paper studies an oligopoly game, where firms can choose between pricetaking and price-making strategies. On a mixed market price takers are always better off than price makers, though the profits of both types decline in the number of price takers. We investigate and confront two possibilities of firms' decisions about their types: forward-looking equilibrium reasoning and backward-looking individual learning. We find that the Cournot outcome is the only equilibrium prediction and it is learnable if firms are sufficiently sensitive to profit differences. However, with a larger number of firms, a unilateral deviation from Cournot behavior becomes profitable. Under learning this incentive creates a space for permanent oscillations over different markets with a positive but low number of price takers.
\end{abstract}

Keywords: Evolutionary oligopoly; Individual Learning; Cournot-Nash equilibrium

JEL Classification: C63, C72, D43, D83.

\footnotetext{
*This paper would not have been written without Carl Chiarella's interest and stimulating discussions about our previous work on learning in oligopolies. We would like to thank two anonymous reviewers for their suggestions and critical questions that helped us improving the paper. We also thank Jan Tuinstra for useful feedback and usual encouragement. Mikhail Anufriev acknowledges financial support from the Australian Research Council through Discovery Project DP140103501. Dávid Kopányi acknowledges support from the Open Research Area project on Behavioral and Experimental Analyses in Macro-finance (BEAM).

${ }^{\dagger}$ Phone: +61 29514 4078, E-mail: Mikhail.Anufriev@uts.edu.au.

†Phone: +31 20525 4214, E-mail: d.kopanyi@uva.nl, corresponding author
} 


\section{Introduction}

Oligopolies are very complex market structures. Consider, for example, an established industry where a homogeneous good is produced by several profit-maximizing firms with identical cost structure and where both demand and cost structure is a common knowledge. There is no one, commonly agreed descriptive model of firms' behavior even for this idealized environment. Firms might take into account how their production decisions affect prices, as they do in Cournot competition or if they collude. Or, at another extreme, firms may take price as given and behave competitively. Even if price-making behavior brings firms higher profits, ${ }^{1}$ the recent literature casts doubts on whether this behavior will actually be observed. A celebrated result by Vega-Redondo (1997) states that the Cournot-Nash equilibrium is not evolutionary stable. That is if firms use trial and error and adapt via imitation of the most profitable firm, the dynamic process moves them away from the Cournot outcome and bring the market to the Walrasian point, which corresponds to the equilibrium under price-taking firms. Results in Huang (2003, 2007) show that a firm that deviates from collusive behavior unilaterally to be a price taker will earn a higher profit than the collusive firms.

In this paper we contribute to the literature by studying market dynamics when firms decide to be one of the two types (price maker or price taker) and reconsider the choice over time on the basis of own and, in some cases, all firms' past experience. Methodologically our paper belongs to the growing literature on heuristic switching models in which boundedly rational myopic agents switch between several modes of behavior (see Brock and Hommes, 1997; Anufriev and Hommes, 2012; Hommes, 2013). It is also closely related to the literature on reinforcement learning in games (see Erev and Roth, 1998 and Camerer and Ho, 1999). We place our paper in the current literature on oligopolies in Section 2.

To focus on the firms' decisions about their types, we study the simple and standard case of linear demand and linear marginal cost oligopoly as introduced in Section 3. The firms know the demand and cost functions and produce a perishable homogeneous good. Production takes time which means that price-taking firms should form expectations about the next period price to make their production decisions. Price makers know the market composition and produce optimally given this composition. We shall mostly assume that the expectations of price takers are naive, though the case of perfect foresight is also discussed. ${ }^{2}$ We are interested in

\footnotetext{
${ }^{1}$ In particular, among all non-collusive outcomes, the firms have the highest profit in the Cournot-Nash equilibrium when they are price-makers.

${ }^{2}$ If all firms are price takers in our model, we obtain a well-known cobweb model that became a standard model to introduce and investigate various expectation schemes, see, e.g., Nerlove
} 
the question whether there exists a market composition under which firms would be, in some sense, satisfied with their types. If such composition does not exist, then we are interested in the time-invariant distribution over types that arises in the long-run and corresponding dynamics of price, total output and relative profits of price-taking and price-making firms. In our model price takers have a higher equilibrium profit than price makers in any market with both types. However, when the number of price takers in the market is too high, the equilibrium becomes unstable and price dynamics converge to a 2-cycle where price makers have much higher average profit than price takers. Given these features, we analyze different versions of the model with firms choosing their types endogenously.

In Section 4 we use game-theoretic approach where firms choose their types in a strategic way, by considering their steady-state profits and choosing the best type given the other firms' types. We introduce a notion of compositionally stable markets, which are Nash equilibria in pure strategies of a game where firms choose their types once and for all. We prove that, with an additional requirement of price dynamics converging to the steady state, the only stable market composition is when each firm is a price maker. Thus, we find support for the Cournot equilibrium but not for the Walrasian equilibrium or for mixed markets where both types coexist. However, we also show that when the number of firms in the industry increases, the Cournot market will eventually lose its compositional stability, as every firm in this market would be better off by becoming a single price taker.

Section 5 is concerned with backward-looking firms' behavior, when each firm makes decision repeatedly, based on profits received in the past. As intuition suggests, when the Cournot market is compositionally stable, then simulations with backward-looking learning tend to converge to the Cournot market. When the Cournot market is compositionally unstable, dynamics do not converge to a fixed composition. In this case we observe oscillations in price and quantities caused by a cyclical switching between types. The number of price takers is typically low to guarantee price stability. At the same time, price makers cannot drive price takers out of the market as price takers earn higher profits than price makers.

Section 6 summarizes the paper. Proofs of some results are presented in the Appendix and additional simulations can be found in the Online Appendix.

(1958), Muth (1961), Bray and Savin (1986), Chiarella (1988), Hommes (1994) and Brock and Hommes (1997). If cobweb dynamics converges, it converges to the Walrasian equilibrium. If all firms are price makers, an immediate outcome is the Cournot-Nash equilibrium. 


\section{Literature Review}

Our paper belongs to a growing economic literature that deals with behavioral oligopolies. Instead of taking an equilibrium point in the strategy space as a granted outcome of firms' interaction, it studies dynamical aspects of firms' learning processes, i.e., firms' adaptive behavior that occurs in actual time. In this literature firms are boundedly rational either because they do not have sufficient information or computational abilities to play an equilibrium strategy or because they may fail to coordinate with their competitors on playing an equilibrium profile. ${ }^{3}$ In this literature firms often rely on some behavioral rules that map their past information to new actions. A typical research question is whether the dynamics generated by the interaction between boundedly rational firms would converge and, if so, where. The literature can be divided into three interrelated streams.

The first stream focuses on adaptive learning of strategic firms. Price-making firms form expectations about the production of the rest of the industry and optimize under their expectations. Expectations are formed based on historical observations. Firms are boundedly rational either because they ignore contemporaneous adjustment by their competitors, or because they have incomplete information about the industry demand function, or both. Indeed, the so-called "naive" adjustment, when every firm plays the best reply to the total production of its competitors in the previous period goes back to Cournot (1838), who focused on a limiting point of such process. ${ }^{4}$ Theocharis (1960) and Hahn (1962) among others, derived several results on the convergence of naive adjustment dynamics to the CournotNash equilibrium. More sophisticated learning schemes have been studied, where the firms adjust their output towards the best reply only partially and/or reply to a historical mean of total output (Huck, Normann, and Oechssler, 1999). This usually enhances convergence to the Cournot-Nash equilibrium. A different approach is used in Chiarella and Szidarovszky (2002, 2004), Bischi, Chiarella, and Kopel (2004), and Bischi, Naimzada, and Sbragia (2007), who study the convergence properties of adjustment processes under the assumption that the demand function is misspecified. ${ }^{5}$ In this setup fast convergence to a steady state typically occurs, though, due to demand misspecification, the steady state may be different from the Cournot-Nash equilibrium.

\footnotetext{
${ }^{3}$ See Bischi, Chiarella, Kopel, and Szidarovszky (2009), Armstrong and Huck (2010) and Kirman (2011) for recent overviews of various branches of this literature. A related field of "behavioral industrial organization" focuses on consequences of cognitive biases of consumers.

${ }^{4}$ That is why naive adjustment is often called Cournot best response dynamics.

${ }^{5}$ Other models with learning in oligopolies under misspecified demand are Kirman (1983), Brousseau and Kirman (1992), and recently Anufriev, Kopányi, and Tuinstra (2013). In these papers firms compete in price, however.
} 
Another branch of the literature applies ideas of evolutionary game theory. In these models the firms' choice of production levels does not involve any strategic considerations $^{6}$ but is solely driven by past profits. This is the framework where such behavioral aspects as experimentation or imitation can be modeled. The focus is on the long-run outcome of the processes and, in particular, which one of the two equilibria, Cournot-Nash or Walrasian, attracts the dynamics. The dynamical process can either be simulated, or can be studied using the tools of stochastic dynamical system. ${ }^{7}$ It turns out that the outcome of the dynamic process depends on the exact assumptions about learning. If firms are engaged in social learning, where they imitate the most successful firms in the previous period, then the process converges to the Walrasian equilibrium, see Vega-Redondo (1997). ${ }^{8}$ On the other hand, if firms experience individual learning and can only be involved in hypothetical or actual experimentation with own strategies, then the outcome may be different. ${ }^{9}$

In the first stream of literature the firms' behavior is strategic, whereas in the second stream non-strategic firms choose an action that worked best in the past. The third stream combines these two ideas. Similar to the first stream, firms can use more or less sophisticated behavioral rules. And similar to the second, their behavior is driven by the relative past profits, but now they select over behavioral rules. The main interest here lies in the dynamics of market composition (i.e., distribution over the rules) and in the resulting price and quantity dynamics. For instance, Droste, Hommes, and Tuinstra (2002) consider the Cournot duopoly, where firms choose between two rules: a non-sophisticated "naive adjustment" rule, that produces the best reply on the previous output, and a very sophisticated "Nash" rule that is the profit maximizing equilibrium strategy given the current

\footnotetext{
${ }^{6}$ Firms do not have to know how many opponents are there in the market, what their demand curve is, etc.

${ }^{7}$ The examples of the latter approach are Vega-Redondo (1997), Schenk-Hoppé (2000) and Alós-Ferrer (2004). As technical tools can be applied to a limited range of situations, the agentbased approach as used in Vriend (2000), Arifovic and Maschek (2006), Riechmann (2006) and Vallée and Yıldızoğlu (2009) is often more insightful.

${ }^{8}$ This is surprising as every firm has the smallest possible profit in that equilibrium. This result is often attributed to the spite effect emerging under imitation, when a profit-decreasing experimentation of a firm can be sustained and even imitated simply because other firms have even larger decrease in profits than the experimenting firm. Alós-Ferrer (2004) shows that if firms in Vega-Redondo (1997) setting can remember profits of all firms from the previous two or more periods, the evolutionary process can converge to any point between the Walrasian and Cournot-Nash equilibria. This suggests that the Walrasian outcome is produced not only by the spite effect, but also when the memory of imitating firms is very short (one period only).

${ }^{9}$ In Vriend (2000) the dynamics with individual learning converges to the Cournot-Nash equilibrium, whereas in Arifovic (1994) and Arifovic and Maschek (2006) it converges to the Walrasian equilibrium. See Vallée and Yıldızoğlu (2009) for reconciliation of the results.
} 
market composition. Both rules have the Cournot-Nash equilibrium as the steady state. Nevertheless, if the "Nash" rule is costly and the best reply function is steep enough, then evolutionary competition between the two rules may lead to cyclical or even chaotic dynamics. ${ }^{10}$ This model has been extended to the case of oligopolies in Hommes, Ochea, and Tuinstra (2011). It turns out that the Cournot-Nash equilibrium is destabilized with an increasing number of firms in the industry. ${ }^{11}$

It is common in this stream to study two competing rules with the same steady state. Instead, in our model the two modes of behavior have different equilibria, the Cournot-Nash and the Walrasian equilibria. It relates us to an important earlier work in Huang $(2002,2003){ }^{12}$ These papers analyze the market with a price taker and more sophisticated (e.g., price-making) firms and show that price takers always make a higher profit than sophisticated firms. This result suggests that the price-taking behavior maybe advantageous for the firms and invites to study incentives of firms to switch their behavioral types and investigate the properties of their dynamical type selection process. This is the path we follow in this paper. ${ }^{13}$

Specifically, we ask the question: What type of distribution between two commonly used modes of behavior, price-taking and price-making, would prevail in the markets? Can the case be made to support one of the homogeneous markets (i.e., one of those two equilibria)? We deliberately simplify other aspects of the environment by assuming linear demand and marginal cost functions, as well as common knowledge of them and of the market composition. This distinguishes us from many contributions discussed in this section, though we share with them the dynamic nature of the model, learning aspect of the firms, and the main question of interest. In particular, we differ from the first stream of literature as in our model all firms know the demand function. This is a natural assumption for well established industries. Moreover, we assume that the price makers use correct (i.e., equilibrium) strategies for a given market composition. Again, this is plausible on established and transparent markets, where more sophisticated firms gather information about strategies employed by less sophisticated firms. Consequently, we do not touch the issue of stability of the Cournot-Nash equilibrium under adaptive

\footnotetext{
${ }^{10}$ The underlying intuition is simple. "Naive adjustment" rule, being cheaper, is more popular near the steady state but under this rule the steady state is unstable. "Nash" rule, becomes more popular far from the steady state, and brings dynamics back close to the equilibrium.

${ }^{11}$ See also Bischi, Lamantia, and Radi (2015) and Baiardi, Lamantia, and Radi (2015).

${ }^{12}$ We thank an anonymous reviewer for pointing out these contributions.

${ }^{13}$ Huang $(2007,2008 \mathrm{~b})$ study dynamics in the model with price takers and price makers, where price takers use a cautious quantity adjustment process. These alternatives lead to different dynamic patterns than in our paper. Explicit type selection is analyzed in Huang (2010), though under a very different learning mechanism than what we use in Section 5.
} 
learning, but in our model other equilibria are also possible because some firms can be price takers. In our model firms are more farsighted than in the models of the second stream. Indeed, our firms learn which type (or mode of behavior) they want to choose and not their production level. We will see that under such learning Cournot-Nash equilibrium can be stable and the spite effect disappears.

Even if our model naturally belongs to the third stream of the literature, there are several important differences both in setup and methodology from other papers. Apart from absence of adaptive learning by the price makers, we do not employ a so-called "random matching setup" typical for other papers and, instead, work directly with integer number of firms. ${ }^{14}$ Moreover, we investigate individual learning of the firms about their types, as this requires less information, which is reasonable in case when some types are non-sophisticated.

\section{The Model}

We consider an industry with $N \geq 2$ firms indexed by $i=1, \ldots, N$ producing a homogeneous good and facing a linear (inverse) demand function

$$
p_{t}=\max \left\{a-b Q_{t}, 0\right\}, \quad a, b>0,
$$

where $p_{t}$ is the price and $Q_{t}$ is the total quantity produced at period $t$. Firms have an identical cost structure. At each period of time, the firms' cost functions are quadratic:

$$
C_{i}\left(q_{i, t}\right)=\frac{s q_{i, t}^{2}}{2}, \quad s>0
$$

where $q_{i, t}$ is the quantity produced by a single firm so that $Q_{t}=\sum_{i} q_{i, t}$.

The structure of production is of the standard type for the cobweb model. That is production takes one period and the commodity cannot be stored after it has been produced. Therefore, every firm $i$ should make at the end of period $t-1$ the decision on which quantity $q_{i, t}$ it should produce and supply to the market at time $t$. To make this decision, a firm should decide which type it wants to be.

\footnotetext{
${ }^{14}$ In the spirit of evolutionary game theory and for the technical reasons rather than by motives of realism, it is common to model interactions of few firms via replicator dynamics, i.e., as an outcome of random matching from a continuum set of firms. One recent example is Radi (2017), where an evolutionary learning between the same types as in our paper is studied. Working with integer number of firms makes the model less artificial but comes at the cost that formal dynamic analysis of the learning model is intractable. Thus, after characterizing stable equilibria we rely on computer simulations.
} 
There are two types of firms on the market, price takers (or non-strategic firms) and price makers (or strategic firms) and firms decide their types at the end of period $t-1$. We will specify their decision process in Section 5, after analyzing the model with fixed types. The number of price-taking firms at time $t$ is denoted as $n_{t} \in\{0,1, \ldots, N\}$. The remaining $N-n_{t}$ firms are price makers.

Price-taking firms are non-strategic in the sense that they do not take other firms into account when choosing their quantities to maximize their profits. Due to the lagged production structure, at the end of period $t-1$ these firms form price expectations $p_{t}^{e}$ for period $t$ and then produce the quantity $q$ that maximizes $p_{t}^{e} q-C(q)$. Two cases can be considered. Under perfect foresight price-taking firms predict price correctly, $p_{t}^{e}=p_{t}$. However, this requires strong assumptions on information and computational abilities, which would contradict our notion of a low degree of sophistication of price-taking firms. The perfect foresight assumption can also be justified as a limiting point of a boundedly rational price rule. Indeed, we will assume that the expectations of the price-taking firms are naive, so that $p_{t}^{e}=p_{t-1}$. When the price dynamics converges with time to a constant price, naive expectations would generate perfect foresight. Under naive expectations, every price-taking firm produces in period $t$

$$
q_{t}^{P T}=\frac{p_{t-1}}{s} .
$$

Price-making firms are strategic because they take into account the presence of other firms in the market. They are assumed to know the exact industry composition. Every price-making firm knows the total supply from the price-taking firms, $n_{t} q_{t}^{P T}$, and sets its quantity as in the Cournot model by solving

$$
\max _{q_{i, t}}\left\{\left(a-b\left(q_{i, t}+Q_{-i, t}+n_{t} q_{t}^{P T}\right)\right) q_{i}-s q_{i}^{2} / 2\right\},
$$

where $Q_{-i, t}$ is the quantity produced by the remaining price makers at time $t$. Standard calculations show that the production level of every price-making firm in the symmetric equilibrium is

$$
q_{t}^{P M}=\max \left\{\frac{a-b n_{t} q_{t}^{P T}}{s+b\left(N-n_{t}+1\right)}, 0\right\} .
$$

Finally, we determine the market clearing price in period $t$ as

$$
p_{t}=\max \left\{a-b\left(n_{t} q_{t}^{P T}+\left(N-n_{t}\right) q_{t}^{P M}\right), 0\right\} .
$$

When the price as well as the quantities are non-negative, it becomes

$$
p_{t}=a-b\left(n_{t} \frac{p_{t-1}}{s}+\left(N-n_{t}\right) \frac{a-b n_{t} p_{t-1} / s}{s+b\left(N-n_{t}+1\right)}\right) .
$$


Price depends on the market composition (the number of price takers and price makers) at a given period and also on the past price. The latter dependence is caused by the naive price expectations of price-taking firms. ${ }^{15}$

\section{Fixed Market Composition}

In this section we study the case of fixed market composition, with $n_{t} \equiv n$ pricetaking and $N-n$ price-making firms. In this case the price dynamics described by (3) is one-dimensional and linear. It has a unique steady state with price

$$
p(n)=\frac{a s(s+b)}{s^{2}+b s(N+1)+b^{2} n},
$$

where price takers and price makers produce the quantities

$$
q^{P T}(n)=\frac{a(s+b)}{s^{2}+b s(N+1)+b^{2} n}, \quad q^{P M}(n)=\frac{a s}{s^{2}+b s(N+1)+b^{2} n},
$$

respectively. The corresponding profits of the two types are

$$
\pi^{P T}(n)=\frac{s a^{2}(s+b)^{2}}{2\left(s^{2}+b s(N+1)+b^{2} n\right)^{2}}, \quad \pi^{P M}(n)=\frac{s^{2} a^{2}(s+2 b)}{2\left(s^{2}+b s(N+1)+b^{2} n\right)^{2}} .
$$

These formulas incorporate the two limiting special cases. If all firms are price takers, i.e., $n=N$, the price dynamics (3) reduces to $p_{t}=a-b N p_{t-1} / s$, which gives rise to the cobweb dynamics. At the steady state the price, individual quantities and individual profits are given by

$$
p^{W}:=\frac{a s}{s+b N}, \quad q^{W}:=\frac{a}{s+b N}, \quad \pi^{W}:=\frac{a^{2} s}{2(s+b N)^{2}},
$$

respectively. ${ }^{16}$ In the other special case all firms are price makers, i.e., $n=0$. Then we are in the standard Cournot-Nash equilibrium, where the price, individual quantities and individual profits are given by

$$
p^{C N}:=\frac{a(s+b)}{s+b(N+1)}, \quad q^{C N}:=\frac{a}{s+b(N+1)}, \quad \pi^{C N}:=\frac{1}{2} \frac{a^{2}(s+2 b)}{(s+b(N+1))^{2}},
$$

respectively. On the basis of these calculations we have the following result.

\footnotetext{
${ }^{15}$ If price-taking firms would have perfect foresight about the price, $p_{t}^{e}=p_{t}$, then we can solve the previous equation for price to obtain $p_{t}=a s(b+s) /\left(s^{2}+b s(N+1)+b^{2} n_{t}\right)$. This is just the steady state under naive expectations, see (4).

${ }^{16}$ The superscript $W$ refers to the Walrasian equilibrium that we have in this competitive case.
} 
Proposition 4.1. Consider the steady state of a market with $0 \leq n \leq N$ pricetaking and $N-n$ price-making firms. Then:

1. The price, individual firms' quantities and profits are given by (4), (5), and (6) above, and are decreasing in the number of the price-taking firms.

2. Total production and consumer surplus increase with the number of pricetaking firms.

3. Price-taking firms produce more than price-making firms and receive higher profits in any mixed market composition.

The statements of this proposition can be confirmed by direct computations, but the underlying intuition is also simple. In the mixed market with $N$ firms, price makers take the production of the price-taking firms as given and coordinate on the Nash equilibrium given the residual demand. ${ }^{17}$ Understanding that they have an impact on the price, price makers will cut their production and produce less than they would produce as price takers. Therefore, the total output is always higher with more price takers, and, as their number increases, the price falls from $p^{C N}$ to $p^{W}$. Hence, the total production

$$
Q(n)=n q^{P T}(n)+(N-n) q^{P M}(n)=\frac{a(s N+b n)}{s^{2}+b s(N+1)+b^{2} n}
$$

will increase ${ }^{18}$ with $n$ from $N q^{C N}$ to $N q^{W}$. Since price falls and total production increases with $n$, the impact of the number of price takers on the consumers' surplus

$$
C S(n)=\frac{1}{2}(a-p(n)) Q(n)=\frac{1}{2} \frac{a^{2} b(s N+b n)^{2}}{\left(s^{2}+b s(N+1)+b^{2} n\right)^{2}}
$$

is undoubtedly positive. Finally, for a fixed market composition, given the price $p(n)$, price takers produce the profit maximizing output and, hence, receive higher profit than price makers. ${ }^{19}$

\footnotetext{
${ }^{17}$ The behavior of price makers is thus similar to the behavior of followers in the Stackelberg model. In our model, however, the price takers are not rational leaders, as they do not take the price makers' decisions into account.

${ }^{18}$ Note that as the number of price takers increases, we have two opposing effects on the total production. The negative effect is due to the fact that with a new market composition both price takers and price makers will produce less. The positive effect is due to the increased relative weight of price takers as they always produce more than price makers. Direct computations show that $p^{\prime}(n)<0$ and $Q^{\prime}(n)>0$, so that the positive effect dominates.

${ }^{19}$ Huang (2002) shows that the price taker has a higher profit than the price maker in duopoly
} 


\subsection{Local stability analysis}

Proposition 4.1 characterizes the steady state of price dynamics (3), which is always consistent with the perfect price foresight of price takers. Under our assumption of naive expectations, the steady state can be justified as a limiting point in time, but only in the case if it is stable. The next result addresses the question of stability.

Proposition 4.2. Consider price dynamics in (3) in the market with $n_{t} \equiv n$ price takers and $N-n$ price makers. There are two possibilities:

1. If $\mathrm{Nb} / \mathrm{s}<1$, the steady state (4) is locally stable for any $n$.

2. If $N b / s \geq 1$, there is a threshold value $n^{c} \leq N$ such that the steady state (4) is locally stable if $n<n^{c}$ and unstable if $n>n^{c}$.

In the latter case with $n>n^{c}$, the dynamics converges to a locally stable 2-cycle with price interchanging between $p_{1}=0$ and $p_{2}=a(s+b) /(s+b(N-n+1))$. Along this cycle price takers make a negative average profit whereas price makers make a positive average profit.

Proof. See Appendix A.1, where we derive the threshold value $n^{c}$, see (A.2), as well as the production quantities and profits along the 2-cycle.

The market with no price-taking firms is not affected by their price expectations and hence it is stable. Proposition 4.2 shows that price-taking firms may destabilize the market as their number increases. Condition $\mathrm{Nb} / \mathrm{s}<1$ is the standard stability condition in the cobweb model with naive expectations. ${ }^{20}$ When it is not satisfied, there is a threshold in the number of price takers. Above it, the price dynamics diverges to the 2 -cycle being equal to 0 at every other period.

We illustrate the dynamics of price and quantities on the market with a fixed composition of total $N=10$ firms in Figure 1. For the chosen parameters (see the caption), the threshold value is $n^{c}=4.69$ and so the dynamics is stable for $n \leq 4$

and calls this result "naiver's paradox". Subsequent work (Huang, 2003, 2007, 2011) showed that the paradox can be generalized for oligopolies with a decreasing demand and increasing, strictly convex cost function of firms. Furthermore, the price-taking strategy outperforms also other sophisticated firms, including collusive and dynamically optimizing price makers.

${ }^{20}$ Indeed, every price-taking firm has a linear supply function with slope $1 / s$. Hence $N / s$ is the slope of the aggregate supply when every firm is a price taker. The slope of aggregate demand is $-1 / b$. The absolute ratio of their slopes is $N b / s$. The cobweb model is stable when supply is relatively flat, i.e., when $\mathrm{Nb} / \mathrm{s}<1$. 


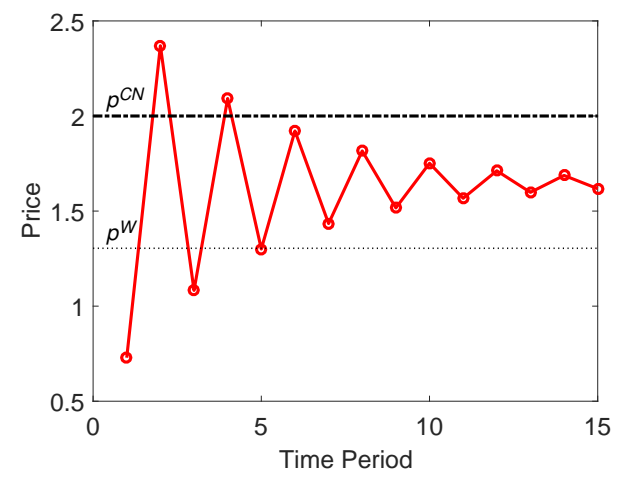

(a) Time series of price for $n=4$

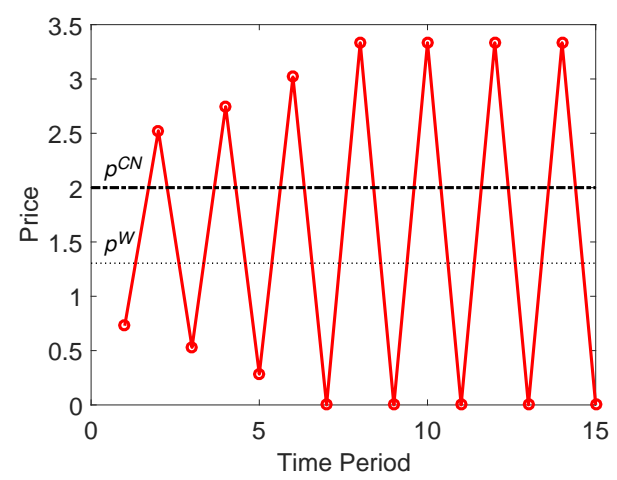

(c) Time series of price for $n=5$.

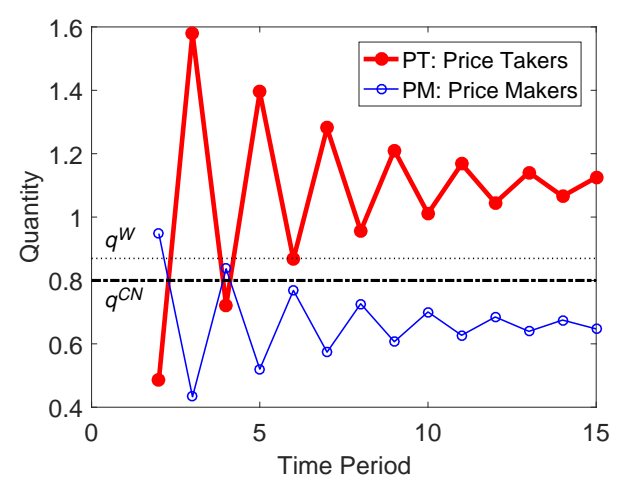

(b) Time series of quantities for $n=4$.

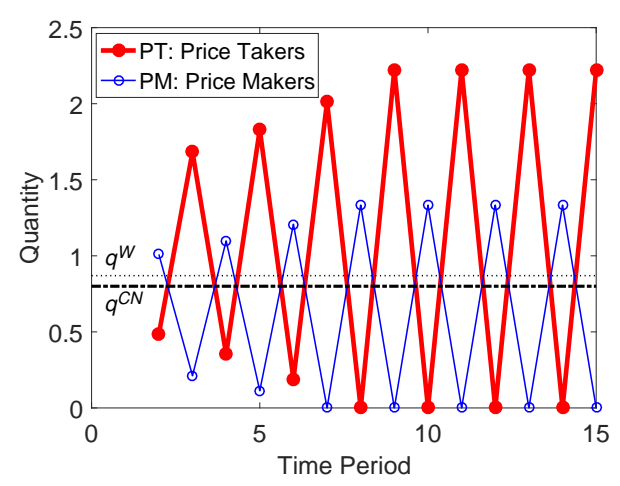

(d) Time series of quantities for $n=5$.

Figure 1: Time series of prices (left panels) and quantities (right panels) for different values of the number of price takers, $n$, in the market with $N=10$ firms. Upper panels: Convergence to the steady state. Lower panels: Convergence to the 2-cycle. Two vertical lines show the price and quantities in the Cournot-Nash $(n=0)$ and Walrasian $(n=10)$ equilibria. Market parameters: $a=10, b=1, s=1.5$ and $N=10$.

and unstable otherwise. The upper panels show the stable case $(n=4)$, when price and quantities converge to the equilibrium values. As stated in Proposition 4.1, the equilibrium price $p(4)$ lies between $p^{W}$ (shown by the dotted line) and $p^{C N}$ (shown by the dashed-dotted line). Price takers produce more than the competitive level of production, whereas price makers produce less than the Cournot-Nash quantity, $q^{W}<q^{P M}(4)<q^{C N}$. The lower panels show the unstable case, $n=5$, when simulations converge to the 2-cycle. Every other period the price-taking firms produce too much, leading to zero price. Their profit is negative, whereas price makers produce and earn nothing. In the following period price takers are inactive, price makers foresee this and respond by producing the optimal quantity. The price is positive and this makes price takers entering the market again in the next period. 


\subsection{Stable markets}

On the market with $N$ firms there are $N+1$ possible market compositions. Which of these compositions is most likely to be observed?

According to Proposition 4.1, in any mixed market price-taking firms are better off than price-making firms. This creates incentives for price makers to switch their type and become a price taker. It seems, therefore, that the market with no price makers would be an outcome of some profit-driven adaptive process by the firms. Moreover, as the total output is maximized in such market, the outcome would be socially optimal, consistent with the largest possible consumer surplus (8). However, there are two reasons why the Walrasian outcome may not be so likely after all. First, after changing their types, firms will find themselves in the new market configuration. Since the profit of price takers decreases with their number, those price makers that decided to become price takers may end up with a lower profit than before. Such outcome would not be satisfactory for them, forcing them to switch back. Second, price dynamics in some market configurations does not converge to the steady state. If so, the steady state profits may not be a right basis for choosing types. We address these points in turn with the following two definitions.

Definition 4.1. A market is called compositionally stable if none of the firms on the market has an incentive to switch its type unilaterally. Formally, the market with $n$ price takers and $N-n$ price makers is compositionally stable if

$$
\pi^{P T}(n) \geq \pi^{P M}(n-1) \quad \text { and } \quad \pi^{P M}(n) \geq \pi^{P T}(n+1) .
$$

Otherwise, the market is called compositionally unstable.

On compositionally stable markets the two conditions are satisfied. First, no pricetaking firm has an incentive to become a price maker (assuming that all other firms do not change their types). Second, no price-making firm has an incentive to become a price taker (assuming that all other firms keep their types unchanged). ${ }^{21}$

Note that the definition of compositionally stable markets involves forwardlooking elements: Firms anticipate their steady-state profits after switching their types. ${ }^{22}$ In Section 5 we will study the dynamics of a model, where firms choose

\footnotetext{
${ }^{21}$ When $n=0$, i.e., every firm is a price maker, only the second inequality is relevant for compositional stability. Similarly, when $n=N$, only the first inequality is relevant. Our definition is closely related to the notion of "dynamically-stable" states as introduced in Huang (2010).

${ }^{22}$ It is easy to see that compositionally stable markets are the pure strategy Nash equilibria of a game where firms choose their types and then get the resulting steady-state profits.
} 
their types on the basis of past profits and, in this sense, are backward-looking. We will observe that the notion we introduced here is useful to describe the long-term outcome of such learning process, but only if firms can learn the steady state profit quickly after switching. In particular, firms will not be able to learn those profits at all, if price dynamics is unstable after switching. For this reason we ramify the notion of compositionally stable markets as follows.

Definition 4.2. A market is called stable if it is compositionally stable and its steady state is locally asymptotically stable.

In the rest of this section we will characterize compositionally stable and stable markets. The next Lemma derives conditions on the number of price-taking firms under which a firm has no incentive to switch its type unilaterally.

Lemma 4.1. Condition $\pi^{P T}(n) \geq \pi^{P M}(n-1)$ is equivalent to

$$
n \geq 1+\left(1+\frac{s}{b}\right) \sqrt{\frac{s}{b}} \sqrt{2+\frac{s}{b}}-\frac{s}{b}(N-1) .
$$

Condition $\pi^{P M}(n) \geq \pi^{P T}(n+1)$ is equivalent to

$$
n \leq\left(1+\frac{s}{b}\right) \sqrt{\frac{s}{b}} \sqrt{2+\frac{s}{b}}-\frac{s}{b}(N-1) .
$$

Proof. See Appendix A.2.

From this lemma it follows that price-taking firms have incentive to become price makers if the number of price takers is low. Instead, price-making firms would be better-off by becoming price takers if the number of price takers is sufficiently high. Using the results of Lemma 4.1 we get the following result about compositionally stable markets.

Proposition 4.3. Mixed markets, in which there are price-taking as well as pricemaking firms $(0<n<N)$ are never compositionally stable.

A market with only price-making firms $(n=0)$ is compositionally stable if and only if

$$
N \leq 1+\left(1+\frac{s}{b}\right) \sqrt{1+2 \frac{b}{s}} .
$$

A market with only price-taking firms $(n=N)$ is compositionally stable if

$$
N \geq 1+\sqrt{\frac{s}{b}} \sqrt{2+\frac{s}{b}} .
$$



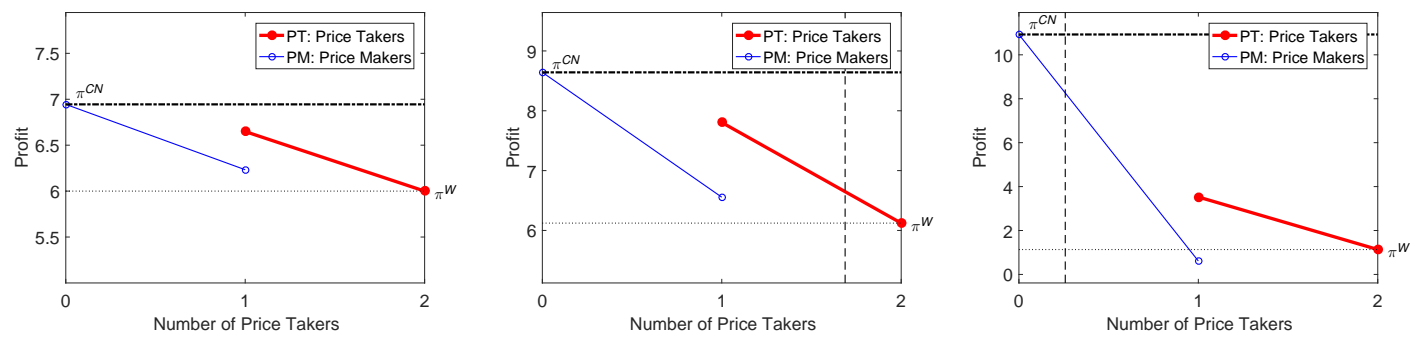

Figure 2: Equilibrium profits of price takers and price makers in case $N=2$ for different slopes of the supply function. Left: Flat supply, $s=3$. Middle: Intermediate supply, $s=1.5$. In both cases, only the market with $n=0$ is compositionally stable. Right: Steep supply, $s=0.1$. Both the markets with $n=0$ and with $n=2$ are compositionally stable. The vertical dashed line in the middle and right panels shows the threshold above which the price dynamics is unstable. Other market parameters: $a=10$ and $b=1$.

Proof. On mixed markets both conditions (9) and (10) should hold, but this is obviously impossible. The market without price takers is compositionally stable only if (10) with $n=0$ is satisfied. This inequality is equivalent to (11). Finally, the market without price makers is compositionally stable only if (9) with $n=N$ is satisfied. This inequality is equivalent to (12).

We illustrate these notions in Figure 2 for the duopoly case. The demand is the same in all three panels, whereas the slope of supply, $1 / s$, is difference and increases from the left panel to the right. The panels show the equilibrium profits of price takers (disks connected by a thick line) and price makers (circles connected by a thin line) as functions of the number of price takers, $n$. The vertical dashed line in the middle and right panels shows the threshold $n^{c}$ from Proposition 4.2. For the market in the left panel the steady state of price dynamics is stable for every $n$. As supply becomes steeper, the steady state loses stability, first, in the market with $n=2$ (middle panel), and then in the market with $n=1$ (right panel).

Consider, first, the market with only price makers $(n=0)$, which is located at the left edge of each panel. In all three cases this market is compositionally stable $^{23}$ and, hence, stable. Indeed, in all panels of Figure 2 the profit of price makers for $n=0$ (shown by the upper horizontal line) is higher than the profit of the price taker in the mixed market (when $n=1$ ). It implies that the mixed market is compositionally unstable, as the price taker would always prefer to switch to price-making strategy. Finally, consider the market located at the right edge

\footnotetext{
${ }^{23}$ It follows from (11) that a duopoly with no price takers is always compositionally stable.
} 
of each panel, where both firms are price takers earning profit $\pi^{W}$ as shown by the lower horizontal line. Its compositional stability depends on the parameters. The market is compositionally unstable in the left and middle panels (the price maker in the mixed market gets higher profit than $\pi^{W}$ ), but it is compositionally stable on the right panel. However, even in the latter case, the market without price-makers is not stable, as the price dynamics diverge.

Thus in all three cases illustrated in Figure 2, there are no multiple stable markets. It turns out that this is a general result.

Proposition 4.4. The only possible stable market in the model with $N$ firms, linear demand and quadratic cost function is the Cournot market, where each firm is a price maker.

Proof. From Proposition 4.3 it follows that there might be at most two (compositionally) stable markets. In Appendix A.3 we show that the market with only price takers cannot be compositionally as well dynamically stable at the same time.

\subsection{Discussion}

As opposed to the seminal paper of Vega-Redondo (1997), in our model Cournot markets represent the only possible stable configuration. This result can be attributed to an important conceptual difference between the two models in terms of the behavior of firms. In Vega-Redondo's model firms are not strategic, comparing the profits the different options gave in the given period. In contrast, firms are strategic in our model, i.e., they evaluate unilateral deviation on the basis of profits in the new market composition. ${ }^{24}$ To illustrate this difference, consider the case when the Walrasian equilibrium is locally asymptotically stable and suppose that all but one firm are price takers. Would the price maker be willing to switch to price-taking behavior? In our model, this switch does not pay off, because the Walrasian equilibrium is compositionally unstable (as it follows from Proposition 4.4). On the other hand, price takers make a higher profit than the price maker (Proposition 4.1), and if firms were imitating as in Vega-Redondo (1997), the price maker would be willing to switch.

Proposition 4.4 shows that Cournot markets are the only possible stable markets. However, Proposition 4.3 implies that when the total number of firms $N$ increases, the Cournot market loses its compositional stability. In such situation

\footnotetext{
${ }^{24}$ Another difference is that firms choose behavioral types in our model and not the production level as in Vega-Redondo (1997).
} 

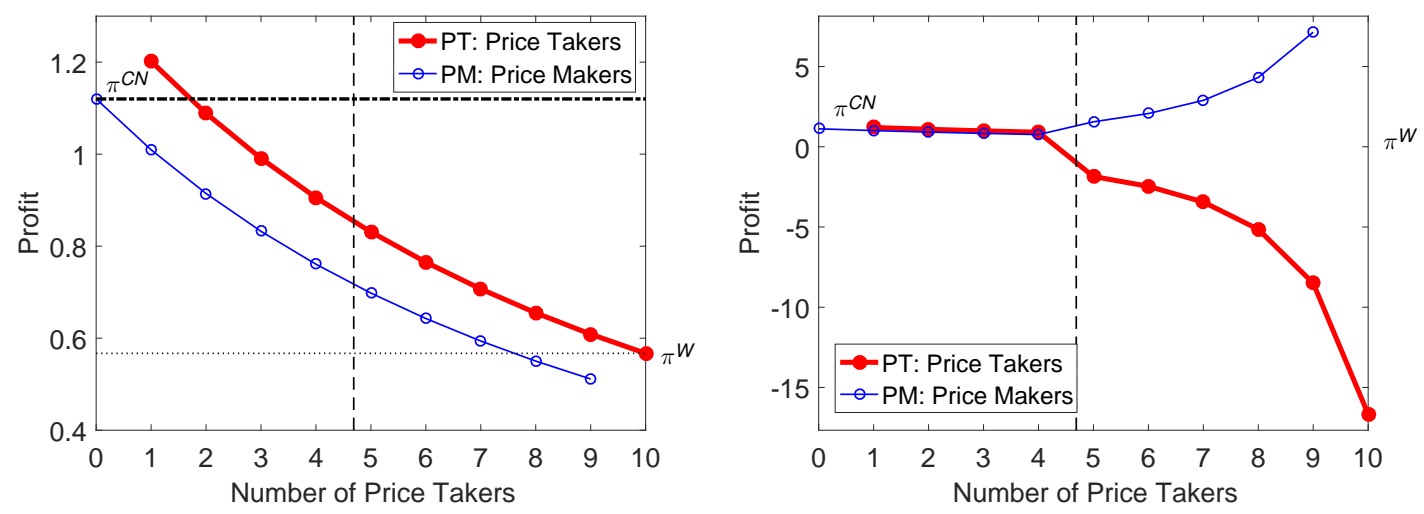

Figure 3: Left: Equilibrium profits of price takers and price makers for different market compositions. Right: Long-run average profits of price takers and price makers for different market compositions. After 9000 transitory steps we compute averages over the next 1000 periods. The steady state is stable to the left from the vertical line, i.e., for $n \leq 4$. Market parameters: $a=10, b=1, s=1.5$ and $N=10$.

no stable market exists, as illustrated in the left panel of Figure 3 for $N=10$ firms. (The other parameters are the same as in the middle panel of Figure 2). When $n=0$, every firm has an incentive to be a single price taker. Thus the market with $n=0$ is compositionally unstable and there is no stable market composition in this example. ${ }^{25}$

The notion of compositional stability is useful to identify the conditions when the Cournot outcome is likely to be observed. However, there are several caveats in using this notion. First, Definition 4.1 uses equilibrium profits. These profits might not be a right measure if price expectations of firms are not rational. That is why we introduced the notion of stable markets in Definition 4.2. Alternatively, one could define compositional stability using the long-run average profits. The right panel of Figure 3 shows the simulated long-run average profits for the same market with $N=10$ firms as in the left panel. ${ }^{26}$ We observe that price makers do not want to switch in the market with $n=4$ price takers. Thus, this market configuration can also be considered as a candidate for stability, if firms have non-rational expectations.

\footnotetext{
${ }^{25}$ Huang (2010) introduces a different kind of switching dynamics where firms evaluate unilateral deviations and the type choice of one firm from each group is implemented at the same time, leading to a new market composition. Under this switching mechanism not only stable markets can occur but also more complicated attracting sets.

${ }^{26}$ For $n \leq 4$ the averages coincide with the steady state profits. For $n>4$ these are the averages over the limiting 2-cycles, as described in Proposition 4.2.
} 
Nevertheless, we think that the notion of compositional stability, as an equilibrium notion, is more appealing, when defined through equilibrium profits. Even if we do not find rational expectations plausible per se, the naive expectations for the price takers is only one of many possible boundedly rational rules (though the most popular in a model like ours). The same model under adaptive expectations would have less strict conditions for asymptotic stability of the steady state. ${ }^{27}$ Indeed, our second caveat is that the notion of stable markets in Definition 4.2 depends on our specific assumption about naive expectations for price takers.

The notion of compositional stability is based on the assumption that firms are strategic and forward-looking, i.e., they can a priori deduce their best type and also coordinate. An alternative way to model firms' behavior is to assume that they are backward-looking, deciding their type on the basis of past profit of price-making and price-taking behaviors. Our next step is to investigate whether such learning model can support the strategic notion of compositional stability.

\section{Endogenous Type Selection}

In this section we consider a model where firms learn individually from their own past experience. ${ }^{28}$ As each production rule (i.e., firm's type) may be more or less profitable, we assume that firms can reconsider their types from time to time. Each firm then decides whether to use the more sophisticated price-making rule (that requires information about the market composition and involves equilibrium computations) or the less sophisticated price-taking rule (that only requires solving a simple profit maximization problem). Each firm keeps track of the profits it earned as a price maker or a price taker and uses them when deciding its type in the spirit of reinforcement learning: The rule that was more profitable in the past has a higher chance to be chosen.

\footnotetext{
${ }^{27}$ Under adaptive expectations of price takers, the vertical line in Figure 3 would shift right.

${ }^{28}$ Our learning is similar to the one analysed in Weisbuch, Kirman, and Herreiner (2000), though we allow firms to experiment independently from their past payoffs. In the models of Brock and Hommes (1997, 1998), Vega-Redondo (1997) and Chiarella and He (2002), all agents know the profitabilities of all types and learning is social. Section 2 of the Online Appendix shows that our results obtained under individual learning remain valid under social learning. We discuss the underlying intuition in Section 5.3. Section 3 of the Online Appendix studies the mixed case when price makers are social learners while price takers learn individually. Indeed, one can argue that social learning is plausible for price makers who have all information to compute the profit of both decision rules, but not for price takers (unless the profit information is public). In this paper we focus on individual learning for both types, as we do not want to introduce an extra difference in addition to the difference in production rules.
} 
Formally, we model learning as follows. Assume that firms are allowed to choose their types every $m$ periods, where $m>1$ is an integer number. That is, if firms have chosen their types at the end of period $t$, they will keep their types in periods $t+1, \ldots, t+m$, but will be able to revise their choice at the end of period $t+m$. The assumption of keeping types for multiple periods is made for two reasons. First, when a firm changes its production rule, it is worthwhile to wait several periods to see how this rule performs before revising it again. Second, we expect that firms more easily change their production level than the underlying production rule. ${ }^{29}$

The types are chosen on the basis of performance measures. Suppose firms can choose their types for period $t$. If firm $i$ was a price maker in the previous $m$ periods, then the performance of price making for this firm is given by

$$
U_{i, t-1}^{P M}=(1-\eta)\left(\bar{\pi}_{i, t-1}-C\right)+\eta U_{i, t-1-m}^{P M},
$$

where $\bar{\pi}_{i, t-1}=\frac{1}{2}\left(\pi_{i, t-2}+\pi_{i, t-1}\right)$ is the average profit of firm $i$ over the last two periods, ${ }^{30} C \geq 0$ is a cost of price-making behavior, ${ }^{31}$ and $\eta \in[0,1]$ is a memory parameter. If firm $i$ was a price taker, a similar expression, but without cost, is used to update $U_{i, t-1}^{P T}$. The performance measure of the unused rule is not updated.

Firms choose their next-period type stochastically and independently from each other by completing one of the following two processes:

1. Experimentation: Firm $i$ experiments with a small probability $\lambda \in[0,1]$. When it experiments, the firm chooses either type with $50 \%$ chance.

2. Learning: With probability $1-\lambda$, firm $i$ chooses its type on the basis of own past experience. It decides to be a price taker in period $t$ with probability

$$
P_{i, t}^{P T}=\frac{e^{\beta U_{i, t-1}^{P T}}}{e^{\beta U_{i, t-1}^{P T}}+e^{\beta U_{i, t-1}^{P M}}},
$$

where $U_{i, t-1}^{P T}$ and $U_{i, t-1}^{P M}$ are the performances as defined in (13). The logit function in (14) is based on the standard discrete choice model, see McFadden (1981). Parameter $\beta \geq 0$ is the intensity of choice, measuring how sensitive firms are to profit differences.

\footnotetext{
${ }^{29}$ One can view "quantity produced" as a fast variable and "production rule" as a slow variable.

${ }^{30}$ We update performance measures with the average profit over the last two periods as under a fixed market composition there is convergence either to the equilibrium or to the 2-cycle and for the 2-cycle the average profit is relevant for assessing the performance of the rules.

${ }^{31}$ This parameter captures information gathering and computational costs associated with price-making behavior.
} 
Timing in our model can be summarized as follows.

\section{Initialization:}

An initial price $p_{0}$ is drawn from the uniform distribution on the interval $[0, a]$. Firms' types are predetermined initially: The number of price takers is set to $n_{1}=N / 2$ (when $N$ is even) or to $n_{1}=(N-1) / 2$ (when $N$ is odd). The initial performance measures $U_{0, i}^{P T}$ and $U_{0, i}^{P M}$ are set to $100 .{ }^{32}$

2. In period $t \geq 1$ :

i) Firms make their production choices as described in Section 3:

$$
q_{t}^{P T}=\frac{p_{t-1}}{s} \text { and } q_{t}^{P M}=\max \left\{\frac{a-b n_{t} p_{t-1} / s}{s+b\left(N-n_{t}+1\right)}, 0\right\} .
$$

ii) Price and profits are calculated:

$$
p_{t}=\max \left\{a-b\left(n_{t} q_{t}^{P T}+\left(N-n_{t}\right) q_{t}^{P M}\right), 0\right\} \text { and } \pi_{i, t}=p_{t} q_{i, t}-s q_{i, t}^{2} / 2 .
$$

iii) If $t$ is divisible by $m$, the performance measures are updated as in (13), and firms choose their types as described above. This determines the new market composition for periods $t+1, t+2, \ldots, t+m$.

3. The simulation stops in period $T$.

In the next sections we simulate the model for the same market as in Section 4 (i.e., with $a=10, b=1$ and $s=1.5$ ). Under these parameters the Cournot market is stable when there are $N \leq 4$ firms in the market. ${ }^{33}$

In Section 5.1 we focus on the case $\beta=\infty$ and $\eta=0$, i.e., when firms choose the rule with the highest average profit under the current market composition. We start with this setup, as the firms' incentives for type selection can be understood most clearly in this case. Then in Section 5.2 we investigate the role of the different parameters of the learning model. Finally, in Section 5.3 we analyze type selection under social learning. In each section we simulate the market for $T=10,000$ periods. When we analyze the data from many runs, we always average results from 100 simulations corresponding to different seeds, using the last 1, 000 periods from each of these 100 simulations.

\footnotetext{
${ }^{32}$ To check the robustness of our results, we ran simulations with different initial numbers of price takers too. The results were qualitatively the same. We set initial performance measures relatively high in order the firms could try both rules. We also simulated the model with lower initial as well as with higher initial performances (-100, 0 and 1000). We did not observe substantial changes in the results.

${ }^{33}$ This can be seen from (11) in Proposition 4.3. The middle panel in Figure 2 illustrates the stable situation $(N=2)$. Figure 3 illustrates the unstable situation $(N=10)$.
} 


\subsection{Results with $\beta=\infty$ and $\eta=0$}

We focus on two questions in this section. First, can learning firms coordinate on price-making behavior when the Cournot market is stable? In other words, can backward-looking learning support equilibrium predictions? Second, which market composition will occur when there are no stable markets? Will the market settle down with a mixed composition or will the composition keep on changing?

In order to compare the predictions of Section 4 with the outcome under learning, we set the learning parameters as follow. First, as we assumed in Section 4 that firms in equilibrium choose the type with the highest profit with certainty, we set $\beta=\infty$ and $\eta=0$. In the learning model this corresponds to the binary choice when firms choose the type which had the highest average profit in over the last two periods. Second, as in the compositionally stable equilibria firms use equilibrium profits, we set $m=10$ to let the price dynamics settle after every change of types. Of course, if the price dynamics is not stable, firms will move towards the stable 2-cycle. Finally, we set the cost for price making $C=0$ as additional costs were not considered in the definition of compositional stability. At the end of the section we will discuss that imposing a small positive cost leads to qualitatively the same results.

Figure 4 illustrates the long-run dynamics of price (upper panels) and of the number of price takers (lower panels) in two markets that differ only in the total number of firms. When $N=3$ (left panels), the Cournot market is stable, and, indeed, the market is most often in the Cournot equilibrium with no price takers. Note, however, that the market with 2 price makers and 1 price taker also occurs frequently. It starts with one experimenting firm becoming a price taker, and staying with this rule for a while. ${ }^{34}$ A very different, cyclical pattern is observed for $N=10$ (right panels), when the Cournot market is compositionally unstable. When the number of price takers is low, firms, one by one, switch to become price takers. As the number of price takers exceeds 4, price dynamics become unstable and the number of price takers quickly drops to 0 or 1 . Then, after a while, firms use the price-taking rule again, which results in the cyclical pattern.

We verify that the pattern we described is robust by simulating the model 100 times for $N=3$ and for $N=10$. We then calculate the average profits of price makers and price takers under all observed market compositions, and also study directional changes in the market compositions. Table 1 summarizes our findings. ${ }^{35}$

\footnotetext{
${ }^{34}$ Instead when experimentation causes all firms to adapt the price-taking rule, the price explodes and the firms immediately switch to the price-making rule.

${ }^{35}$ Note that as firms can decide their types every $m=10$ periods and we use only the last
} 

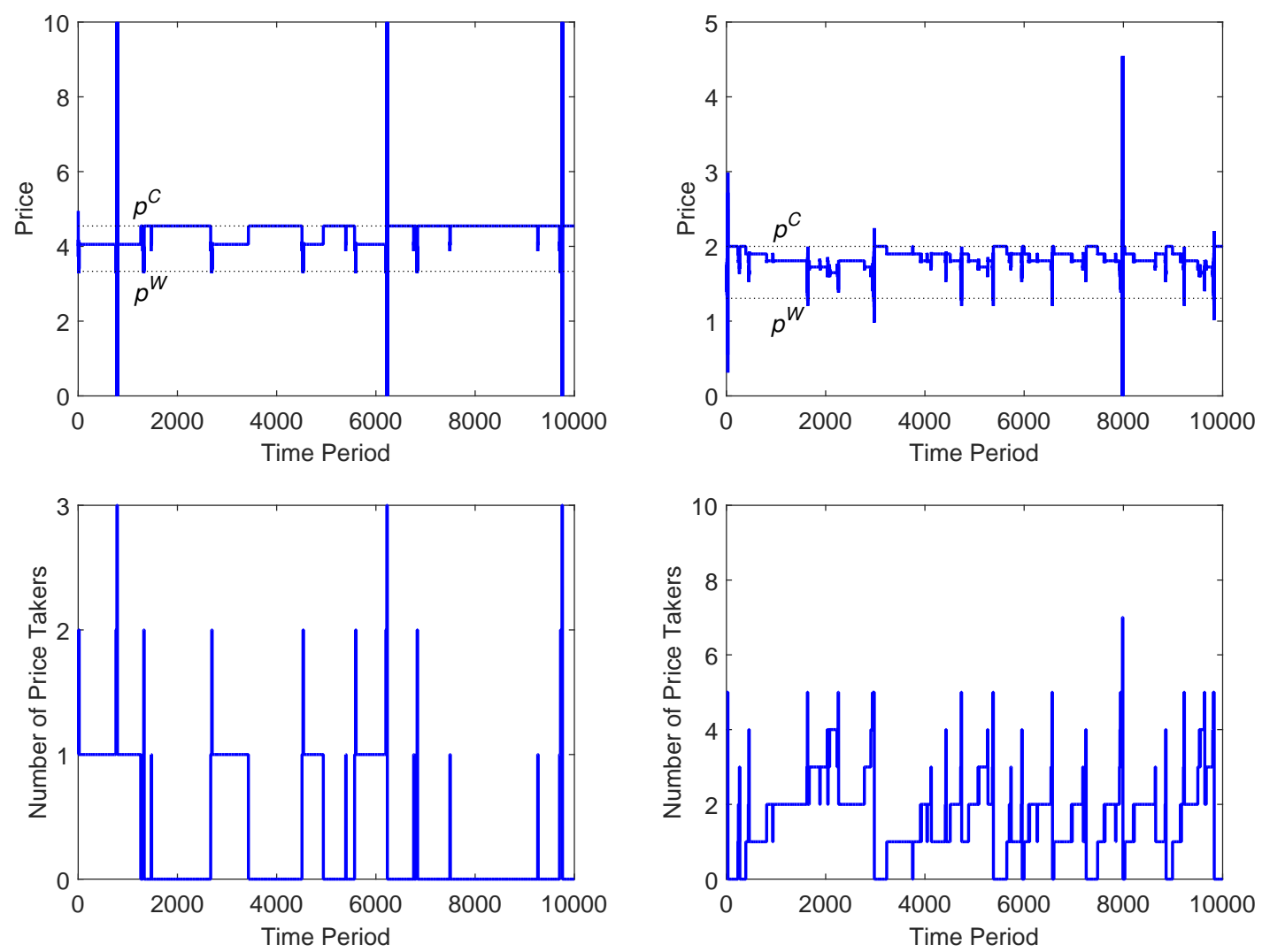

Figure 4: Time series of price (upper panels) and of the number of price takers (lower panels) for different numbers of firms: $N=3$ (left panels) and $N=10$ (right panels). Market parameters: $a=10, b=1$ and $s=1.5$. Learning parameters: $\beta=\infty, \eta=0$, $\lambda=0.01$ and $m=10$.

For $N=3$ the Cournot market gives rise to the highest (average) profit possible. Panel (b) shows how the number of price takers changes under different market compositions, indicating that firms rarely change their types when $n=0$ and $n=1$. These markets are characterized by persistent price dynamics. In contrast, markets with 2 or 3 price takers would not last long, as firms typically switch to the price-making rule. ${ }^{36}$ When $N=10$, the dynamics are quite persistent for $n \leq 4$, especially for $n<3$. Indeed, panel (d) shows that in these cases the

1,000 periods of each of the 100 simulations, Table 1 uses overall 10,000 choices. To calculate average profits, we considered the last 2 periods before firms were allowed to choose types, i.e., the same calculations that the firms use for updating performance measures in (13). To calculate changes in the market composition, we compared the market compositions in those periods only when firms were allowed to choose types.

${ }^{36}$ To see how often the different market compositions occurred, we refer the reader to Table 2. 


\begin{tabular}{c|cc}
$n$ & $\pi^{P M}$ & $\pi^{P T}$ \\
\hline 0 & 5.79 & - \\
1 & 4.60 & 5.49 \\
2 & 3.75 & 4.39 \\
3 & - & -16.67
\end{tabular}

(a) Average profits, $N=3$

\begin{tabular}{c|cc}
$n$ & $\pi^{P M}$ & $\pi^{P T}$ \\
\hline 0 & 1.12 & 0 \\
1 & 1.01 & 1.2 \\
2 & 0.91 & 1.09 \\
3 & 0.83 & 0.99 \\
4 & 0.76 & 0.91 \\
5 & 0.75 & 0.74 \\
6 & 2.07 & -2.47 \\
7 & 2.89 & -3.44 \\
8 & - & - \\
9 & - & - \\
10 & - & -
\end{tabular}

(c) Average profits, $N=10$

\begin{tabular}{c|ccc}
$n$ & decrease & remain & increase \\
\hline 0 & - & $98.6 \%$ & $1.4 \%$ \\
1 & $4.0 \%$ & $92.8 \%$ & $3.3 \%$ \\
2 & $52.3 \%$ & $25 \%$ & $22.7 \%$ \\
3 & $100 \%$ & $0 \%$ & -
\end{tabular}

(b) Switching directions, $N=3$

\begin{tabular}{c|ccc}
$n$ & decrease & remain & increase \\
\hline 0 & - & $95.5 \%$ & $4.5 \%$ \\
1 & $0.3 \%$ & $91.7 \%$ & $7.9 \%$ \\
2 & $3.1 \%$ & $91.1 \%$ & $5.8 \%$ \\
3 & $5.1 \%$ & $85.9 \%$ & $9.0 \%$ \\
4 & $16.3 \%$ & $69.5 \%$ & $14.1 \%$ \\
5 & $89.2 \%$ & $9.6 \%$ & $1.2 \%$ \\
6 & $100 \%$ & $0 \%$ & $0 \%$ \\
7 & $100 \%$ & $0 \%$ & $0 \%$ \\
8 & - & - & - \\
9 & - & - & - \\
10 & - & - & -
\end{tabular}

(d) Switching directions, $N=10$

Table 1: Average profits of price makers and price takers (panels a and c) and the direction of switching (panels $\mathrm{b}$ and $\mathrm{d}$ ) for different market compositions. Market parameters: $a=10, b=1$ and $s=1.5$. Learning parameters: $\beta=\infty, \eta=0, \lambda=0.01$ and $m=10$.

market composition is very likely to remain. Note however from panel (c) that on any such market, any price maker would get a higher profit from switching to the price-taking rule. This explains why an increase in the number of price takers is more likely than a decrease. When $n \geq 5$ the switching price maker will get lower profit from the price-taking rule, than it used to get as a price maker. Moreover, as $n>5$ all price takers experience a large loss (as the price is on the two-cycle). Thus, the number of price takers will immediately significantly decrease.

We have seen that market compositions with a low number of price takers (and hence with stable price dynamics) remain unchanged most of the time. It is then interesting to know which market compositions are most likely to occur. To address this question, we report in Table 2 the distribution of the number of price takers under different total number of firms. We conclude from the table that, when the Cournot market is stable $(N \leq 4)$, it will be the most frequent 


\begin{tabular}{c|cccccccc}
$N$ & $n=0$ & $n=1$ & $n=2$ & $n=3$ & $n=4$ & $n=5$ & $n=6$ & $n=7$ \\
\hline 2 & 98.2 & 1.4 & 0.4 & - & - & - & - & - \\
3 & 79.3 & 19.6 & 0.9 & 0.2 & - & - & - & - \\
4 & 76.3 & 22.3 & 1.1 & 0.2 & 0.1 & - & - & - \\
5 & 12.2 & 31.5 & 55.3 & 0.9 & 0.1 & - & - & - \\
6 & 19.2 & 39.6 & 28.8 & 11.9 & 0.5 & - & - & - \\
7 & 19.5 & 40.2 & 28.8 & 10.9 & 0.6 & - & - & - \\
8 & 15.4 & 44.2 & 32.8 & 6.0 & 1.2 & 0.4 & 0.1 & - \\
9 & 18.1 & 38.3 & 29.7 & 11.4 & 2.0 & 0.6 & - & - \\
10 & 17.8 & 30.2 & 32.7 & 14.1 & 4.2 & 0.8 & 0.2 & 0.1
\end{tabular}

Table 2: Distribution of the number of price takers under different market size $N$. Market parameters: $a=10, b=1$ and $s=1.5$. Learning parameters: $\beta=\infty, \eta=0$, $\lambda=0.01$ and $m=10$.

realization under individual learning. In the opposite case, when there is no stable market, there will be no single market composition that stands out from the others. Still, the number of price takers will always be low and markets with unstable price dynamics barely ever occur.

Let us now elaborate on how a positive cost for price making affects the results. Notice that dynamic stability does not depend on $C$. Imposing costs affects profitability only: Price making will be less profitable so the corresponding profit curve in Figure 3 shifts downwards. When the number of firms $N$ is low such that the Cournot market is compositionally stable, then the Cournot market may lose its compositional stability if the cost of price making is sufficiently high, as it will be profitable for a firm to switch to price taking unilaterally. Simulations ${ }^{37}$ show that in this case the market converges towards a fixed composition with a small but positive number of price takers.

When the Cournot market is compositionally unstable, then costs do not affect our results qualitatively. Since price makers make a lower profit under stable dynamics already for $C=0$, imposing a small cost increases the profit difference between the decision rules. On the other hand, price makers make substantially larger average profits under unstable dynamics. Consequently, if $C$ is not too high, then price makers have a profit advantage also in this case. Simulations show that the same cyclical process occurs. Price makers tend to become price takers, this destabilizes the dynamics and then firms switch back to the price-making rule. Due to experimentation, more and more firms become price takers again and the cycle starts again.

\footnotetext{
${ }^{37}$ We report simulation results under $C>0$ in Section 4 of the Online Appendix.
} 



Figure 5: Frequency of different market compositions over 1,000 periods after 9,000 transitory periods of 100 different initializations when firms do not experiment $(\lambda=0)$. Rows correspond to different values of $\eta(0$ and 0.25$)$ whereas columns correspond to different values of $\beta$ (1, 5 and 10). Other parameters: $m=10, a=10, b=1$ and $s=1.5$.

\section{$5.2 \quad$ Effects of Individual Learning parameters}

To understand the effects of the model parameters, we consider three different values for the intensity of choice parameter $\beta$ (1,5 and 10), three different values for the memory parameter $\eta(0,0.25$ and 0.5$)$ and two different values for the probability of experimentation $\lambda$ ( 0 and 0.01$)$. We focus on the case of $N=10$ firms, when there are no stable markets. All other parameters are the same as in the previous section. Figures 5 and 6 show the histograms of market compositions under these parameter combinations.

By comparing the two sets of figures, we can immediately conclude that experimentation has a large influence on the market outcome. In particular, if $\beta$ is high, and firms cannot experiment (Figure 5), the market almost always arrives at the Cournot outcome, but if they can experiment (Figure 6), the Cournot outcome does not stand out so clearly. The reason for this difference is the following. When firms do not experiment, they might get locked up with price making in case if their price-taking experience was bad. This is what happens in our simulations: When too many firms switch to price taking, then the dynamics is destabilized, resulting in very low profits. Firms start to perceive price-taking as very unprofitable and hence will always choose price-making. In contrast, if firms may experiment, then they can switch back to price-taking and might find it more profitable to do so. 

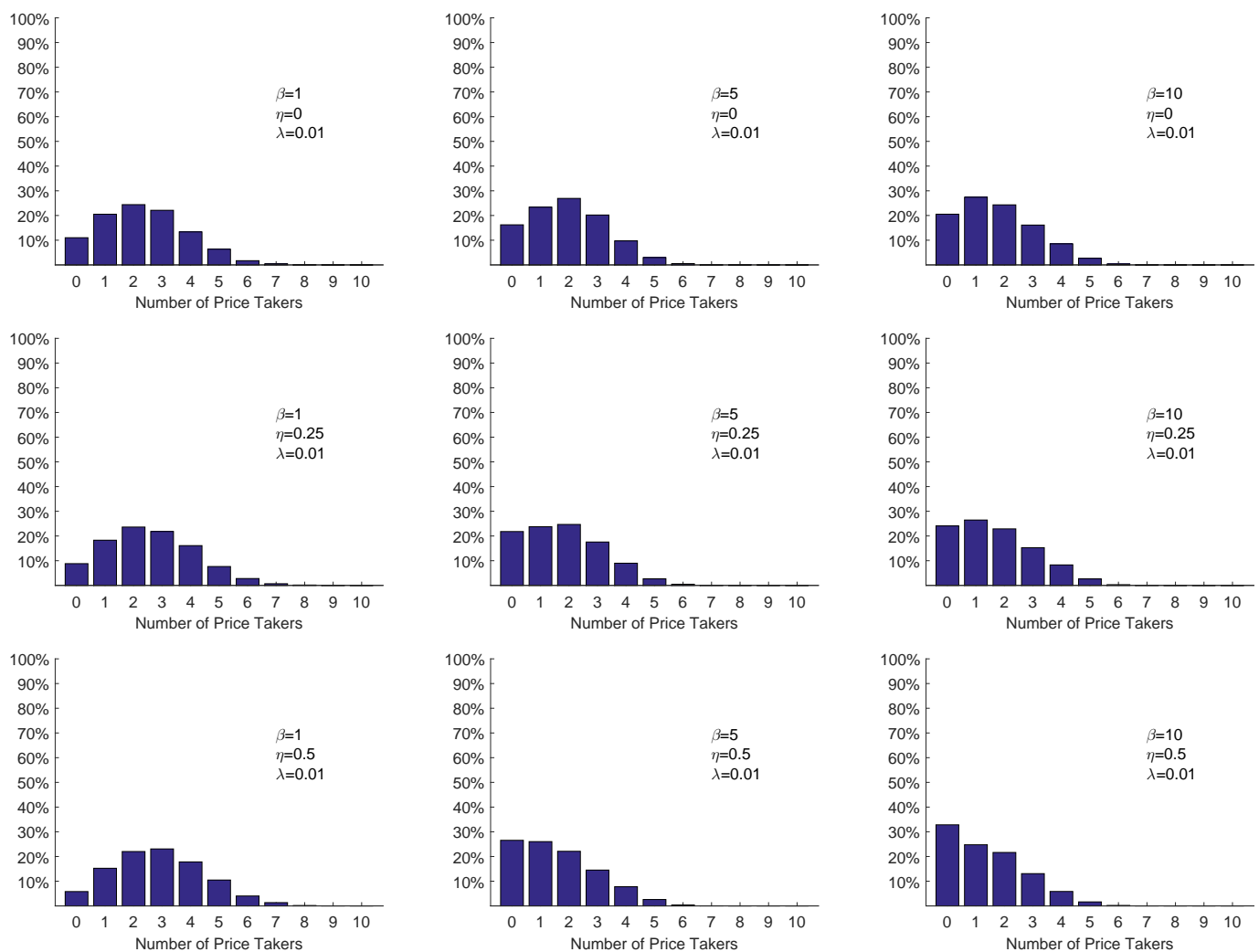

Figure 6: Frequency of different market compositions over 1000 periods after 9000 transitory periods of 100 different initializations under experimentation $(\lambda=0.01)$. Rows correspond to different values of $\eta(0,0.25$ and 0.5$)$ whereas columns correspond to different values of $\beta(1,5$ and 10). Other parameter values: $m=10, a=10, b=1$ and $s=1.5$.

We conclude that experimentation has a crucial role in the learning process as without experimentation firms may get locked up with a specific rule simply because the alternative rule performed badly in a period when they used it. ${ }^{38}$ Thus, firms must experiment to get a correct view about the profitability of the production rules. For this reason we will focus on the simulations with experimentation when analyzing the effects of $\beta$ and $\eta$.

\footnotetext{
${ }^{38}$ The results with no experimentation are also sensitive to the initial number of price takers. For the histograms in Figures 5 and 6 we started with $n=5$ price takers in the first period. This leads to unstable dynamics, so that all 5 firms will experience very low profit from price-taking, and will never return to it again. However, if we start with another number of price takers, then the firms that faced stable dynamics under price making may switch back to price taking at later periods, and price-taking behavior will not be driven out by price making.
} 
In simulations of Section 5.1 we considered a special case of the model with the intensity of choice parameter $\beta=\infty$. However, firms may choose types using also some idiosyncratic information which corresponds to the finite positive value of the intensity of choice. Figure 6 shows that markets with fewer price takers occur more frequently as $\beta$ increases. The intuition behind this result is the following. As $\beta$ increases, firms become more sensitive to profit differences. When there are many price takers in the market, the price dynamics is unstable, resulting in low profits for price takers. Consequently, price takers have higher incentives to switch to being price makers when $\beta$ is higher and more firms will switch to price making.

Memory has a similar effect: As $\eta$ increases, the market composition shifts towards a lower number of price takers. To understand this result, let us recall that price takers make somewhat higher profits than price makers when the number of price takers is low but they make a much lower (average) profit when there are too many price takers in the market. Higher memory has two opposing effects in this case. First, when the dynamics become unstable and price takers make lower profits than before, then fewer price takers will switch their decision rule because they remember the higher past profits they earned as price takers. Second, when many firms switched to be price makers due to the low profitability of price taking, then experimentation does not necessarily turn a price maker into a price taker. If a firm switches to price taking due to experimentation, then it will earn a higher profit. But as it remembers the low profit it earned earlier as a price taker, it might switch back to price making. Based on the histograms the second effect is dominating. This is due to the fact that profit differences between the decision rules are much larger under unstable dynamics, most firms will switch to price making when the dynamics is destabilized.

The switching directions under different parameter combinations, reported in Table 3, further support our findings about the model parameters. The table shows the switching directions under different market compositions for $\beta=1, \eta=0$ and $\lambda=0.01$ (panel a), $\beta=1, \eta=0.5$ and $\lambda=0.01$ (panel b), $\beta=10, \eta=0$ and $\lambda=0.01$ (panel c) and $\beta=10, \eta=0.5$ and $\lambda=0.01$ (panel $\mathrm{d}$ ). By comparing panel (a) with (c) and panel (b) with (d) we find that higher $\beta$ leads to less frequent increase in the number of price takers for $n \leq 4$ and to more frequent decrease in the number of price takers when $n>4$. Both of these effects lead to fewer price takers when $\beta$ is high. To see the effect of memory, we compare panels (c) and (d) only as the histograms in Figure 6 show that memory has only very minor effect on the market composition for $\beta=1$. From the tables we can conclude that a decrease in the number of price takers is always higher under higher memory and that an increase in the number of price takers is lower for $n \leq 4$. Both of these results are in line with our previous discussion about the effect of memory. 


\begin{tabular}{c|ccc}
$n$ & decrease & remain & increase \\
\hline 0 & - & $38.1 \%$ & $61.9 \%$ \\
1 & $14.6 \%$ & $31.5 \%$ & $53.9 \%$ \\
2 & $25.2 \%$ & $29.4 \%$ & $45.4 \%$ \\
3 & $41.2 \%$ & $26.9 \%$ & $31.8 \%$ \\
4 & $60.3 \%$ & $21.8 \%$ & $18.0 \%$ \\
5 & $81.6 \%$ & $11.8 \%$ & $6.6 \%$ \\
6 & $100 \%$ & $0 \%$ & $0 \%$ \\
7 & $100 \%$ & $0 \%$ & $0 \%$ \\
8 & $100 \%$ & $0 \%$ & $0 \%$ \\
9 & - & - & - \\
10 & - & - & -
\end{tabular}

\begin{tabular}{c|ccc}
$n$ & decrease & remain & increase \\
\hline 0 & - & $18.6 \%$ & $81.4 \%$ \\
1 & $8.8 \%$ & $22.0 \%$ & $69.2 \%$ \\
2 & $22.2 \%$ & $23.9 \%$ & $53.9 \%$ \\
3 & $33.5 \%$ & $25.2 \%$ & $41.3 \%$ \\
4 & $50.3 \%$ & $23.3 \%$ & $26.4 \%$ \\
5 & $73.8 \%$ & $17.2 \%$ & $9.1 \%$ \\
6 & $99.8 \%$ & $0.2 \%$ & $0 \%$ \\
7 & $100 \%$ & $0 \%$ & $0 \%$ \\
8 & $100 \%$ & $0 \%$ & $0 \%$ \\
9 & $100 \%$ & $0 \%$ & $0 \%$ \\
10 & - & - & -
\end{tabular}

(a) $\beta=1, \eta=0, \lambda=0.01$

(b) $\beta=1, \eta=0.5, \lambda=0.01$

\begin{tabular}{c|ccc}
$n$ & decrease & remain & increase \\
\hline 0 & - & $69.6 \%$ & $30.4 \%$ \\
1 & $13.0 \%$ & $48.6 \%$ & $38.4 \%$ \\
2 & $27.7 \%$ & $34.9 \%$ & $37.4 \%$ \\
3 & $37.6 \%$ & $31.2 \%$ & $31.1 \%$ \\
4 & $62.3 \%$ & $23.1 \%$ & $14.7 \%$ \\
5 & $93.7 \%$ & $5.9 \%$ & $0.4 \%$ \\
6 & $100 \%$ & $0 \%$ & $0 \%$ \\
7 & $100 \%$ & $0 \%$ & $0 \%$ \\
8 & - & - & - \\
9 & - & - & - \\
10 & - & - & -
\end{tabular}

(c) $\beta=10, \eta=0, \lambda=0.01$

\begin{tabular}{c|ccc}
$n$ & decrease & remain & increase \\
\hline 0 & - & $77.7 \%$ & $22.3 \%$ \\
1 & $19.2 \%$ & $43.1 \%$ & $37.7 \%$ \\
2 & $33.3 \%$ & $35.5 \%$ & $31.1 \%$ \\
3 & $46.7 \%$ & $31.4 \%$ & $22.0 \%$ \\
4 & $67.9 \%$ & $21.5 \%$ & $10.6 \%$ \\
5 & $94.5 \%$ & $4.9 \%$ & $0.6 \%$ \\
6 & $100 \%$ & $0 \%$ & $0 \%$ \\
7 & $100 \%$ & $0 \%$ & $0 \%$ \\
8 & - & - & - \\
9 & - & - & - \\
10 & - & - & -
\end{tabular}

(d) $\beta=10, \eta=0.5, \lambda=0.01$

Table 3: Direction of switching for different market compositions under different specifications of the learning model. Other parameters: $m=10, a=10, b=1$ and $s=1.5$.

\subsection{Social learning}

So far we have assumed that firms are learning individually, i.e., their choice of production rule depends on their own experience. However, as we know from the literature, the outcome of a model may be quite different under individual and social learning. Therefore we elaborate on how our results would change under social learning, when firms know the profits of both types in each period. The corresponding simulations are reported in Section 2 of the Online Appendix. 
As information about profitability spreads faster under social learning than under individual learning, changes in the market composition will also be faster. To see this, consider a market where both types, price makers and price takers, are present. If the price dynamics is stable, price takers earn a higher profit than price makers (Proposition 4.1) and due to social learning, each firm will become a price taker as soon as firms can choose types. ${ }^{39}$ But this may destabilize the price dynamics (case 2 in Proposition 4.2) in which case the profit of every firm is very low. Consequently, each firm will later switch to the price-making rule and we arrive at the Cournot market. After that a firm may become a price taker due to experimentation. It will earn a higher profit and, hence, all other firms will switch to the price-taking production rule again. Then the cycle repeats itself.

Social learning does not lead to the Walrasian equilibrium even when the latter is dynamically stable (case 1 in Proposition 4.2). This is because the memory is built in our learning model even when $\eta=0 .{ }^{40}$ Recall that profits of both types of firms are decreasing in the number of price takers. Assume now that in the initial period some firms are price makers while other firms are price takers. As price takers make a higher profit, every firm becomes a price taker at the period when they are allowed to choose types. Even though price dynamics are stable, firms still make a lower profit than the price makers had in the initial periods. As the performance measure of price-makers is not updated, every firm will become a price maker next time when they can choose a type. Later a firm may experiment and switch to the price-taking rule. As it will make a higher profit now, every firm will become a price taker. But it means that again all firms ended up with a lower profit than before, and they all will switch back to the price-making rule.

To sum up, under social learning the firms are at the Cournot equilibrium most of the time with other market compositions occurring only temporarily, caused by experimentation. Thus the outcome under social learning is the same as under individual learning, though the transition towards the Cournot market is faster. This discussion illustrates that the difference between our results and those of VegaRedondo (1997) stems from memory inherent for the learning process, regardless whether it is individual or social. In Vega-Redondo's model the Walrasian equilibrium is stochastically stable because firms forget the higher profits they earned with lower quantities. In our model the Walrasian equilibrium is unstable because firms never forget the profit they earned as price makers, which is higher than in the Walrasian equilibrium.

\footnotetext{
${ }^{39}$ We explain the intuition behind the results assuming that $\beta=\infty$ and $\eta=0$. The incentives and choices of firms are the clearest in this case.

${ }^{40}$ Indeed, the performance of the rule that is not used in a given period is not updated and stays the same as it was during the last period when the rule has been used.
} 


\section{Conclusion}

Theoretical literature distinguishes between competitive price-taking and strategic price-making firms' behavior. It is typical to study the models where all firms are price takers or, alternatively, all firms are price makers, but it is, in practice, unclear how firms can coordinate on their mode of behavior. We have addressed this question in this paper using a mixture of analytical tools (with forward-looking equilibrium notions) and simulations (with backward-looking learning).

We have considered the oligopolistic industry where firms are heterogeneous in their type or "mode" of behavior. Some firms follow the price-taking production strategy. They set production in a competitive way taking price as given. Other firms follow the price-making production strategy by studying the market composition, i.e., how many firms are price-taking and how many firms are price-making, and playing an equilibrium best response.

We have introduced the notion of stable markets to characterize market compositions in which none of the firms have an incentive to switch their types unilaterally and the resulting equilibrium is locally stable under naive price expectations. We have formally proved that the only possible stable market is the Cournot market, where each firm is a price maker. On the contrary, the market with price takers only is never stable, and, therefore, we do not find support for the Walrasian equilibrium. The Cournot market loses its stability as the number of firms in the market increases. This is due to the fact that it will be more profitable for a firm to switch to price-taking when the number of firms is high enough. In such situation there are no stable markets because as the number of price takers increases, price dynamics is destabilized.

In order to investigate whether firms can learn to be price makers when the Cournot market is stable, we have run computer simulations. We have also investigated how the market composition evolves when there are no stable markets. Our results show that backward-looking learning, when firms independently choose their production types based on the past profits, frequently leads to the Cournot market when it is stable. Thus, firms can coordinate on price-making behavior. When there are no stable markets, then the market does not evolve to a fixed composition but the number of price takers is typically low. In such cases the market composition follows a cyclical pattern which is related to the (in)stability of naive expectations. When there are only a few price takers, then some firms switch to the price-taking rule due to experimentation. They then earn a higher profit than price makers and stay as price takers. At some period, however, the number of price takers will be too high and this destabilizes price dynamics, leading to low 
profits for the price-taking firms. Then most price takers switch back to being a price maker and the cycle repeats itself. This pattern is quite robust: We have seen it both under individual and social learning and for different parameterizations. Our simulations have shown that experimentation has a crucial effect in this process. When firms do not experiment with their types, then they might get locked up with price making if they once earned low profits with price taking.

The analysis in this paper can be extended in several ways. We focused on specific demand and cost structures and we assumed that price takers form naive expectations. It would be interesting to know whether our results can be generalized to other demand and cost structures and expectational schemes (adaptive or heterogeneous expectations). In order to compare our equilibrium reasoning of Section 4 and learning of Section 5, we assumed that price makers know the market composition in each period. However, it might be reasonable to assume that price makers form expectations about the new market composition and base their production choice on these expectations. This extension is definitely interesting but we leave it to future work. Similarly to Huang $(2007,2008 \mathrm{~b}, \mathrm{a})$ one could consider a model where price takers follow cautious quantity adjustment, with an upper bound on the rate of output change. Huang (2008a) shows that more complex dynamics can occur under cautious adjustment and that price takers may earn a higher average profit than price makers even when the static equilibrium is locally unstable.

Another important extension of the model could be to analyze whether policy makers can stabilize the market composition when the Cournot market is compositionally unstable. This could be implemented by adjusting profit taxes, as proposed by Schmitt and Westerhoff (2015). The rationale for stabilizing the market composition is to reduce price volatility. Also, policy makers could drive the market composition towards the one that gives rise to the highest consumer surplus or total surplus under the given number of firms. As the main focus of our paper is how firms can coordinate their mode of behavior in the market, this extension is out of the scope of our current paper and therefore we leave it for future research. 


\section{References}

Alós-Ferrer, C. (2004): "Cournot versus Walras in dynamic oligopolies with memory," International Journal of Industrial Organization, 22(2), 193-217.

Anufriev, M., And C. Hommes (2012): "Evolutionary selection of individual expectations and aggregate outcomes in asset pricing experiments," American Economic Journal: Microeconomics, 4(4), 35-64.

Anufriev, M., D. Kopányi, And J. Tuinstra (2013): "Learning cycles in Bertrand competition with differentiated commodities and competing learning rules," Journal of Economic Dynamics 63 Control, 37(12), 2562-2581.

ARIFovic, J. (1994): "Genetic algorithm learning and the cobweb model," Journal of Economic Dynamics \& Control, 18(1), 3-28.

ArIfovic, J., AND M. K. MascheK (2006): "Revisiting individual evolutionary learning in the cobweb model-an illustration of the virtual spite-effect," Computational Economics, 28(4), 333-354.

Armstrong, M., And S. HuCK (2010): "Behavioral economics as applied to firms: a primer," Competition Policy International, 6, 3-45.

Baiardi, L. C., F. Lamantia, and D. Radi (2015): "Evolutionary competition between boundedly rational behavioral rules in oligopoly games," Chaos, Solitons $\&$ Fractals, 79, 204-225.

Bischi, G.-I., C. Chiarella, and M. Kopel (2004): "The long run outcomes and global dynamics of a duopoly game with misspecified demand functions," International Game Theory Review, 6(03), 343-379.

Bischi, G. I., C. Chiarella, M. Kopel, and F. Szidarovszky (2009): Nonlinear Oligopolies: Stability and Bifurcations. Springer Science \& Business Media.

Bischi, G. I., F. Lamantia, And D. Radi (2015): "An evolutionary Cournot model with limited market knowledge," Journal of Economic Behavior \& Organization, 116, 219-238.

Bischi, G. I., A. K. Naimzada, and L. Sbragia (2007): "Oligopoly games with local monopolistic approximation," Journal of Economic Behavior \& Organization, 62(3), 371-388.

Bray, M. M., And N. E. SAvin (1986): "Rational expectations equilibria, learning, and model specification," Econometrica, 54(5), 1129-1160. 
Brock, W., and C. Hommes (1997): "A Rational Route to Randomness," Econometrica, 65(5), 1059-1095.

Brock, W. A., and C. H. Hommes (1998): "Heterogeneous beliefs and routes to chaos in a simple asset pricing model," Journal of Economic Dynamics \& Control, 22(8), 1235-1274.

Brousseau, V., and A. Kirman (1992): "Apparent convergence of learning processes in mis-specified games," in Game Theory and Economic Applications, ed. by B. Dutta, D. Mookherjee, T. Parthasarathy, T. Raghavan, D. Ray, and S. Tijs. Springer-Verlag.

Camerer, C., and T. H. Ho (1999): "Experience-weighted attraction learning in normal form games," Econometrica, 67(4), 827-874.

Chiarella, C. (1988): "The cobweb model: Its instability and the onset of chaos," Economic Modelling, 5(4), 377-384.

Chiarella, C., And X.-Z. He (2002): "Heterogeneous beliefs, risk and learning in a simple asset pricing model," Computational Economics, 19(1), 95-132.

Chiarella, C., and F. Szidarovszky (2002): "The birth of limit cycles in nonlinear oligopolies with continuously distributed information lags," in Modeling Uncertainty: An Examination of Stochastic Theory, Methods, and Applications, ed. by M. Dror, P. L'Ecuyer, and F. Szidarovszky, pp. 249-268. Springer.

(2004): "Dynamic oligopolies without full information and with continuously distributed time lags," Journal of Economic Behavior \&6 Organization, 54(4), 495-511.

Cournot, A.-A. (1838): Recherches sur les principes mathématiques de la théorie des richesses par Augustin Cournot. Hachette, Paris, (English translation: Researches into the Mathematical Principles of the Theory of Wealth. Kelley, New York, 1960).

Droste, E., C. Hommes, and J. Tuinstra (2002): "Endogenous fluctuations under evolutionary pressure in Cournot competition," Games and Economic Behavior, 40(2), 232-269.

Erev, I., And A. E. Roth (1998): "Predicting how people play games: Reinforcement learning in experimental games with unique, mixed strategy equilibria," American Economic Review, 88(4), 848-881.

Hahn, F. H. (1962): "The stability of the Cournot oligopoly solution," The Review of Economic Studies, 29(4), 329-331. 
Hommes, C. (2013): Behavioral rationality and heterogeneous expectations in complex economic systems. Cambridge University Press.

Hommes, C. H. (1994): "Dynamics of the cobweb model with adaptive expectations and nonlinear supply and demand," Journal of Economic Behavior 86 Organization, 24(3), 315-335.

Hommes, C. H., M. I. Ochea, and J. Tuinstra (2011): "On the stability of the Cournot equilibrium: an evolutionary approach," Discussion paper, University of Amsterdam.

HuAnG, W. (2002): "On the incentive for price-taking behavior," Management Decision, 40(7), 682-692.

(2003): "A naive but optimal route to Walrasian behavior in oligopolies," Journal of Economic Behavior $\mathcal{E}$ Organization, 52(4), 553-571.

(2007): "Profitability analysis of price-taking strategy in disequilibrium," Discrete Dynamics in Nature and Society, 2007.

(2008a): "The long-run benefits of chaos to oligopolistic firms," Journal of Economic Dynamics and Control, 32(4), 1332-1355.

(2008b): "Triumph over your rivals in dynamic oligopoly," Discrete Dynamics in Nature and Society, 2008.

(2010): "On the complexity of strategy-switching dynamics," Journal of Economic Behavior 83 Organization, 75(3), 445-460.

_ (2011): "Price-taking behavior versus continuous dynamic optimizing," Journal of Economic Behavior \& Organization, 78(1), 37-50.

Huck, S., H.-T. Normann, and J. Oechssler (1999): "Learning in Cournot oligopoly-An experiment," The Economic Journal, 109(454), 80-95.

Kirman, A. (1983): "On mistaken beliefs and resultant equilibria," in Individual Forecasting and Collective Outcomes, ed. by R. Frydman, and E. Phelps, pp. 147-166. Cambridge University Press.

ledge.

McFadden, D. (1981): "Econometric models of probabilistic choice," in Structural Analysis of Discrete Data with Econometric Applications, ed. by C. F. Manski, and D. McFadden. MIT Press: Cambridge, MA. 
Muth, J. F. (1961): "Rational expectations and the theory of price movements," Econometrica, 29(3), 315-335.

Nerlove, M. (1958): "Adaptive expectations and cobweb phenomena," The Quarterly Journal of Economics, 72(2), 227-240.

RADI, D. (2017): "Walrasian versus Cournot behavior in an oligopoly of boundedly rational firms," Journal of Evolutionary Economics, 27, 933-961.

Riechmann, T. (2006): "Cournot or Walras? Long-run results in oligopoly games," Journal of Institutional and Theoretical Economics, 162(4), 702-720.

Schenk-Hoppé, K. R. (2000): "The evolution of Walrasian behavior in oligopolies," Journal of Mathematical Economics, 33(1), 35-55.

Schmitt, N., And F. Westerhoff (2015): "Managing rational routes to randomness," Journal of Economic Behavior \& Organization, 116, 157-173.

Theocharis, R. D. (1960): "On the stability of the Cournot solution on the oligopoly problem," The Review of Economic Studies, 27(2), 133-134.

Vallée, T., And M. YildizoĞLu (2009): "Convergence in the finite Cournot oligopoly with social and individual learning," Journal of Economic Behavior 85 Organization, 72(2), 670-690.

Vega-Redondo, F. (1997): "The evolution of Walrasian behavior," Econometrica, 65(2), 375-384.

VRIEND, N. J. (2000): "An illustration of the essential difference between individual and social learning, and its consequences for computational analyses," Journal of Economic Dynamics \& Control, 24(1), 1-19.

Weisbuch, G., A. Kirman, and D. Herreiner (2000): "Market organisation and trading relationships," Economic Journal, 110(463), 411-436. 


\section{APPENDIX}

\section{A Proofs and derivations}

\section{A.1 Proof of Proposition 4.2}

From (3) it can be seen that on the market with fixed number $n$ of price takers, the slope of price dynamics is given by

$$
\frac{\partial p_{t}}{\partial p_{t-1}}=-b\left(\frac{n}{s}-(N-n) \frac{b n / s}{s+b(N-n+1)}\right)=-\frac{b n}{s} \cdot \frac{s+b}{s+b(N-n+1)} .
$$

This derivative is negative and the local stability condition is

$$
\frac{b n}{s} \cdot \frac{s+b}{s+b(N-n+1)}<1 .
$$

Consider, first, the case when $N b / s<1$. Then, since $n \leq N$, we have

$$
\frac{b n}{s} \cdot \frac{s+b}{s+b(N-n+1)} \leq \frac{b N}{s} \cdot \frac{s+b}{s+b(N-N+1)}=\frac{b N}{s}<1,
$$

so that the local stability condition (A.1) holds. Next, assume $N b / s \geq 1$. The condition (A.1) can be rewritten in terms of $n$ as $n<n^{c}$, where the critical value $n^{c}$ is defined as

$$
n^{c}:=\frac{s}{b} \cdot \frac{s+b(N+1)}{2 s+b}=\frac{N+1+s / b}{2+b / s}
$$

Generally when $n<n^{c}$ the steady state is stable and when $n>n^{c}$ it is unstable. When $n^{c}$ is integer, the case when $n=n^{c}$ is a boundary situation. As the map is linear, the steady state is not asymptotically stable. Indeed, there is a continuum of cycles of period 2 in this case. Note that since $s / b \leq N$, the value in (A.2) is less than or equal to $(N+1+N) /(2+1 / N)=N$.

The price function in (4) is linear, and when $n>n^{c}$ its slope becomes less than -1 . Dynamics will then diverge until either price or the quantity of price makers reach their lower bound 0 . Let us first assume that at some point $t$ the quantity $q_{t}^{P M}=0$. From (2) it follows that $\left(a-b n q_{t}^{P T}\right) /(s+b(N-n+1))<0$ which is possible only when $a-b n q_{t}^{P T}<0$. But then $p_{t}=\max \left\{a-b n q_{t}^{P T}, 0\right\}=0$. Thus it is sufficient to assume that at some period $t$ price $p_{t}=0$ and study the dynamics in the following periods. 
Let $p_{t}=0$. Then $q_{t+1}^{P T}=0$ and $q_{t+1}^{P M}=a /(s+b(N-n+1))$, and therefore

$$
p_{t+1}=a-b(N-n) \frac{a}{s+b(N-n+1)}=\frac{a(s+b)}{s+b(N-n+1)}>0 .
$$

Then in the next period we have

$$
q_{t+2}^{P T}=\frac{1}{s} \cdot \frac{a(s+b)}{s+b(N-n+1)} \quad \text { and } \quad q_{t+2}^{P M}=\max \left\{\frac{a-b n q_{t+2}^{P T}}{s+b(N-n+1)}, 0\right\},
$$

and find price

$$
p_{t+2}=\max \left\{a-b\left(n q_{t+2}^{P T}+(N-n) q_{t+2}^{P M}\right), 0\right\} \leq \max \left\{a-b n q_{t+2}^{P T}, 0\right\} .
$$

Since we are in the case of unstable steady state, the inequality in (A.1) has an opposite sign and, hence,

$$
a-b n q_{t+2}^{P T}=a-\frac{b n}{s} \cdot \frac{a(s+b)}{s+b(N-n+1)}=a\left(1-\frac{b n}{s} \cdot \frac{s+b}{s+b(N-n+1)}\right)<0 .
$$

Thus $q_{t+2}^{P M}=0$ and $p_{t+2}=0$. Hence, the dynamics is on the two-cycle with two interchanging points:

$$
\begin{aligned}
& \left(p_{1}, q_{1}^{P T}, q_{1}^{P M}\right)=\left(0, \frac{1}{s} \cdot \frac{a(s+b)}{s+b(N-n+1)}, 0\right) \quad \text { and } \\
& \left(p_{2}, q_{2}^{P T}, q_{2}^{P M}\right)=\left(\frac{a(s+b)}{s+b(N-n+1)}, 0, \frac{a}{s+b(N-n+1)}\right) .
\end{aligned}
$$

We compute profits of both types of the firms in the points of the cycle:

$$
\begin{array}{ll}
\text { when } p=p_{1}: & \pi_{1}^{P T}=-\frac{a^{2}(s+b)^{2}}{2 s(s+b(N-n+1))^{2}}, \quad \pi_{1}^{P M}=0, \\
\text { when } p=p_{2}: & \pi_{2}^{P T}=0, \quad \pi_{2}^{P M}=a^{2} \frac{s / 2+b}{(s+b(N-n+1))^{2}} .
\end{array}
$$

The average profits on the cycle for price takers and price makers are given by

$$
\bar{\pi}^{P T}=-\frac{a^{2}(s+b)^{2}}{4 s(s+b(N-n+1))^{2}} \quad \text { and } \quad \bar{\pi}^{P M}=a^{2} \frac{s / 2+b}{2(s+b(N-n+1))^{2}},
$$

respectively. 


\section{A.2 Proof of Lemma 4.1}

We will show that condition $\pi^{P T}(n) \geq \pi^{P M}(n-1)$ is equivalent to (9). The second part of Lemma will then follow automatically by rewriting (9) for the market with $n+1$ price-taking firm as $\pi^{P T}(n+1) \geq \pi^{P M}(n)$ and then flipping the inequality sign.

Using (6) we have $\pi^{P T}(n)=\alpha \pi^{P M}(n)$ and $\pi^{P T}(n-1)=\beta \pi^{P T}(n)$, where

$$
\alpha=\frac{(s+b)^{2}}{s(s+2 b)} \quad \text { and } \quad \beta=\left(\frac{s^{2}+b s(N+1)+b^{2} n}{s^{2}+b s(N+1)+b^{2}(n-1)}\right)^{2} \text {. }
$$

Hence $\pi^{P M}(n-1)=\beta \pi^{P T}(n) / \alpha$, and inequality $\pi^{P T}(n)<\pi^{P M}(n-1)$ is equivalent to $\alpha<\beta$. Note that $\alpha=1+b^{2} /\left(s^{2}+2 b s\right)$ and $\beta=\left(1+b^{2} / M\right)^{2}$, where the constant $M=s^{2}+b s(N+1)+b^{2}(n-1)>0$. Then we have the following inequality:

$$
\alpha<\beta \quad \Leftrightarrow \quad 1+\frac{b^{2}}{s^{2}+2 b s}<1+2 \frac{b^{2}}{M}+\frac{b^{4}}{M^{2}},
$$

which simplifies to

$$
M^{2}-2\left(s^{2}+2 b s\right) M-b^{2}\left(s^{2}+2 b s\right)<0 .
$$

The discriminant of the last expression is $D=4\left(s^{2}+2 b s\right)(s+b)^{2}>0$. Thus, there are two real roots of the quadratic function in the left part of (A.4):

$$
M_{ \pm}=s^{2}+2 b s \pm(s+b) \sqrt{s^{2}+2 b s} .
$$

Condition (A.4) is satisfied if $M_{-}<M<M_{+}$. It is easy to see that $M_{-}$is always negative, so the condition $M_{-}<M$ holds. The condition $M<M_{+}$leads to

$$
\begin{aligned}
s^{2}+b s(N+1)+b^{2}(n-1) & <s^{2}+2 b s+(s+b) \sqrt{2 b s+s^{2}} \Leftrightarrow \\
\Leftrightarrow \quad n-1 & <\frac{1}{b^{2}}\left((s+b) \sqrt{2 b s+s^{2}}-b s(N-1)\right) \quad \Leftrightarrow \\
\Leftrightarrow n & <1+\left(1+\frac{s}{b}\right) \sqrt{\frac{s}{b} \sqrt{2+\frac{s}{b}}-\frac{s}{b}(N-1) .}
\end{aligned}
$$

which is condition (9).

\section{A.3 Proof of Proposition 4.4}

We will show that the market without price makers $(n=N)$ is never stable. Indeed, if it stable, then $N$ should at the same time satisfy inequality (12) and 
also be less than $s / b$ (from Proposition 4.2). This implies that

$$
\frac{s}{b}>1+\sqrt{\frac{s}{b}} \sqrt{2+\frac{s}{b}}
$$

Let us denote $s / b$ as $x$. Then the inequality above implies that

$$
x>1+\sqrt{x} \sqrt{2+x} \Leftrightarrow\left\{\begin{array}{l}
x>1 \\
x^{2}-2 x+1>2 x+x^{2}
\end{array}\right.
$$

The latest inequality implies that $x<1 / 4$ which is impossible when $x>1$. In Proposition 4.3 we showed that mixed markets are never compositionally stable. Hence, there is only one possible stable market: the one with price makers only. 